\title{
Traumatic tracheal injury after motorcycle accident
}

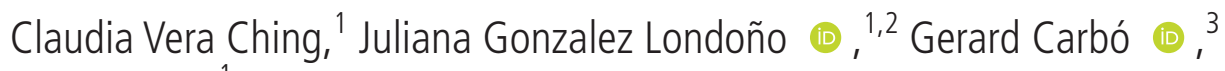 \\ Patricia Ortiz ${ }^{1}$
}

${ }^{1}$ Intensive Care Unit, Doctor Josep Trueta University Hospital of Girona, Girona, Spain ${ }^{2}$ Intensive Care Unit, Santa Caterina Hospital, Salt, Spain ${ }^{3}$ Radiology Department, Doctor Josep Trueta University Hospital of Girona, Girona, Spain

\section{Correspondence to} julianagonzalez.girona.ics@ gencat.cat

Accepted 3 September 2020 Dr Juliana Gonzalez Londoño;

\section{DESCRIPTION}

A 17-year-old patient suffered a motorcycle accident that lead to a direct trauma on the anterior cervical region. On arrival of the ambulance, the patient had laryngeal stridor and generalised hypoventilation but still managed to keep normal oxygen saturation (SpO2) levels. Patient was intubated on site and ventilated with lung protective ventilation (tidal volume of $6 \mathrm{~mL} / \mathrm{kg}$ ), positive end-expiratory pressure of 5 and a fraction of inspired oxygen of 100\%, which allowed him to maintain SpO2 levels of 97\%-98\% throughout the ambulance transfer.

On arrival to the emergency department, his vital signs were stable, but he showed subcutaneous emphysema throughout the cervical, thoracic and abdominal region.

CT scan showed a disruption of the medial onethird of the trachea ( $17 \mathrm{~mm}$ from the jugular notch) of approximately $5 \mathrm{~mm}$, with the orothracheal tube exiting the trachea through the disruption and locating itself anterior to the inferior portion

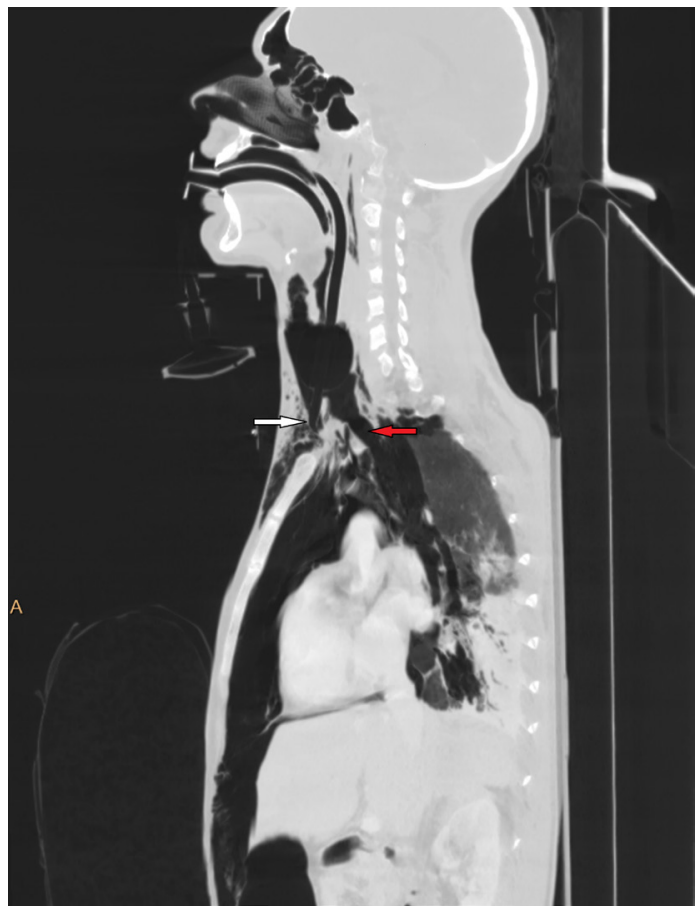

(c) BMJ Publishing Group Limited 2020. No commercial re-use. See rights and permissions. Published by BMJ.

To cite: Vera Ching C,
Gonzalez Londoño J,
Carbó G, et al. BMJ Case
Rep 2020;13:e238895.
doi:10.1136/bcr-2020-
238895

Figure 1 'Minimum intensity projection' in sagittal plain. The entire tracheal route is visualised, showing a disruption of $5 \mathrm{~cm}$ of the middle tracheal third at the level of the cervicothoracic junction. The distal end of the endotracheal tube is located anterior to the trachea (white arrow). The red arrow shows the postdisruption tracheal end. There is abundant subcutaneous emphysema that dissects all the cervicothoracic spaces, continuing to the anterior and middle mediastinum.

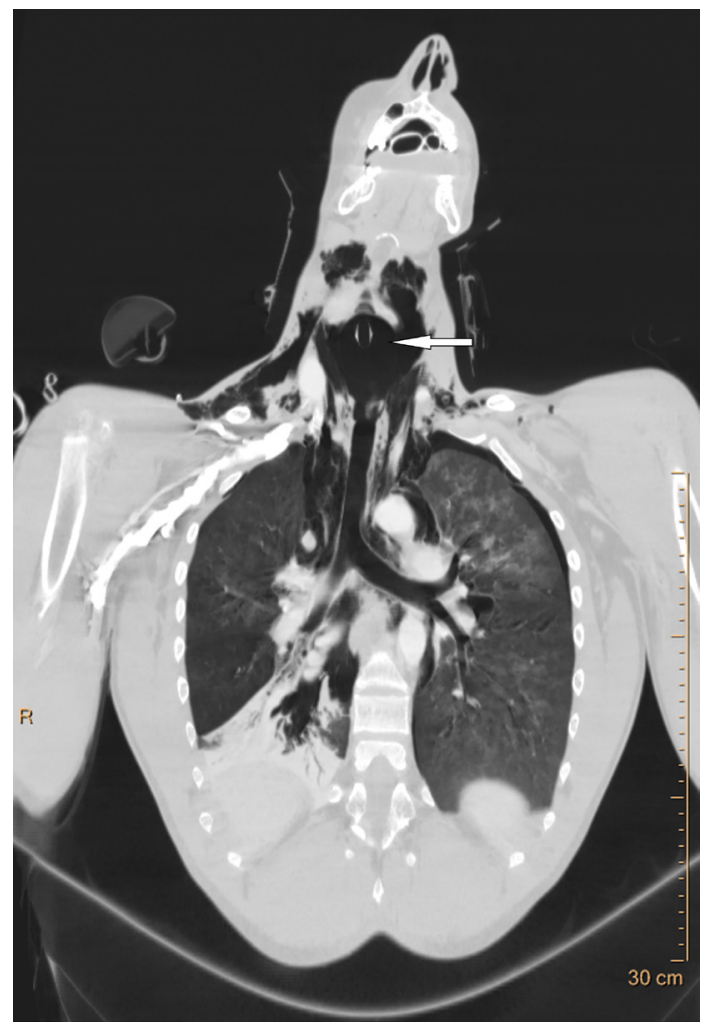

Figure 2 'Minimum intensity projection' in a coronal plain angled anteriorly. The tracheal disruption point is seen just where the balloon of the endotracheal tube is observed (white arrow), creating a partial seal. Presence of abundant subcutaneous emphysema that dissects all the cervicothoracic spaces with continuity to the anterior and middle mediastinum. Moderate left pneumothorax.

of the trachea (figures 1 and 2). The subcutaneous emphysema dissected all the cervicothoracic spaces, continuing to the anterior and middle mediastinum, abdominal wall and the extraperitoneal and transdiaphragmatic spaces in the bilateral subphrenic spaces.

The patient was transferred to the operating room immediately, where a wide anterior cervicectomy was performed. The airway was stabilised by performing a transcervical tracheal intubation. During surgery, a complete disruption of the trachea at the level of the third tracheal ring was confirmed. The Ear, Nose and Throat team performed a terminal-terminal tracheal reconstruction, and the patient was left with a tracheostomy caudal to the tracheal reconstruction.

Two days after the accident, a direct laryngoscopy (flexible laryngoscope) confirmed the integrity of the tracheal reconstruction, and the patient started weaning from mechanical ventilation. On day 8, 
the tracheostomy was removed. A second direct laryngoscopy confirmed the integrity of the suture and a complete paralysis of both vocal cords. He was discharged from the hospital 2 weeks after the accident. A hyperkinetic dysphonia is the only sequelae of his accident.

The true incidence of tracheal injuries (TIs) is unknown as $30 \%-80 \%$ of these trauma victims die at the scene of the accident. ${ }^{12}$ Currently, the incidence of TI among trauma patients with chest and neck injuries, including those who died immediately, is estimated at $0.5 \%-2 \% .{ }^{23}$ The mortality from traumatic TIs has decreased from 36\% before 1950 and 30\% in 1966 to $9 \%$ in $2001,{ }^{1}$ probably due to improvements in prehospital care and early initiation of the Advanced Trauma Life Support protocol. ${ }^{2}$ Surgical management of TIs can be achieved with acceptable mortality, ${ }^{4}$ and most TI can be repaired primarily using a specific surgical approach tailored to the patient's injury. Associated injuries are common, and surgeons must be knowledgeable in treating a wide variety of anatomic abnormalities. ${ }^{5}$ This case brings us a clear example of what existing literature has

\section{Learning points}

- Treating tracheal injuries (Tls) is challenging. An early diagnosis and properly securing the airway are required in order to provide proper ventilation until the repair of the injury can be accomplished

- Surgical management of TIs can be achieved with acceptable mortality, and most TIs can be repaired primarily using a specific surgical approach tailored to the patient's injury.

- Delay in diagnosis is the single most important factor influencing outcome. already stated on this topic: regardless of the anatomic location or the mechanism of the injury, delay in diagnosis is the single most important factor influencing outcome. Recognition of TIs at an early stage and an expedient institution of appropriate surgical intervention are key in these potentially lethal injuries. ${ }^{6}$

\section{Twitter Gerard Carbó @gercarbo}

Acknowledgements The authors would like to thank Mr Felipe Botero for his technical support in formatting the images.

Contributors JGL was the main writer to draft the manuscript; CVC helped draft the manuscript and added significant revisions. CVC and PO were the treating physicians that handled the case. GC was the radiologist related to the case and provided the images and descriptions. All authors read and approved the manuscript.

Funding The authors have not declared a specific grant for this research from any funding agency in the public, commercial or not-for-profit sectors.

Competing interests None declared.

Patient consent for publication Obtained.

Provenance and peer review Not commissioned; externally peer reviewed.

\section{ORCID iDs}

Juliana Gonzalez Londoño http://orcid.org/0000-0001-9071-4004

Gerard Carbó http://orcid.org/0000-0002-3325-4950

\section{REFERENCES}

1 Prokakis C, Koletsis EN, Dedeilias P, et al. Airway trauma: a review on epidemiology, mechanisms of injury, diagnosis and treatment. J Cardiothorac Surg 2014:9:117.

2 Karmy-Jones R, Wood DE. Traumatic injury to the trachea and bronchus. Thorac Surg Clin 2007:17:35-46.

3 Riley RD, Miller PR, Meredith JW. Injury to the esophagus, trachea and bronchus. In: Moore EE, Feliciano DV, Mattox KL, eds. Trauma. New York: McGraw-Hill, 2004: 5. 539-52.

4 Balci $A E$, Eren N, Eren S, et al. Surgical treatment of post-traumatic tracheobronchial injuries: 14-year experience. Eur J Cardiothorac Surg 2002;22:984-9.

5 Johnson SB. Tracheobronchial injury. Semin Thorac Cardiovasc Surg 2008;20:52-7.

6 Cassada DC, Munyikwa MP, Moniz MP, et al. Acute injuries of the trachea and major bronchi: importance of early diagnosis. Ann Thorac Surg 2000;69:1563-7.

Copyright 2020 BMJ Publishing Group. All rights reserved. For permission to reuse any of this content visit

https://www.bmj.com/company/products-services/rights-and-licensing/permissions/

BMJ Case Report Fellows may re-use this article for personal use and teaching without any further permission.

Become a Fellow of BMJ Case Reports today and you can:

- Submit as many cases as you like

- Enjoy fast sympathetic peer review and rapid publication of accepted articles

- Access all the published articles

- Re-use any of the published material for personal use and teaching without further permission

Customer Service

If you have any further queries about your subscription, please contact our customer services team on +44 (0) 2071111105 or via email at support@bmj.com.

Visit casereports.bmj.com for more articles like this and to become a Fellow 